\title{
Kinetic and Spectroscopic Characterization of ACMSD from Pseudomonas fluorescens Reveals a Pentacoordinate Mononuclear Metallocofactor
}

\author{
Tingfeng Li, ${ }^{\ddagger}$ Antoinette L. Walker, ${ }^{\ddagger}$ Hiroaki Iwaki, ${ }^{\S}$ Yoshie Hasegawa,,${ }^{\S}$ and Aimin Liu* ${ }^{*}$ \\ "Department of Biochemistry, University of Mississippi Medical Center, Jackson, MS \\ 39216-4505, and ${ }^{\S}$ Department of Biotechnology, Faculty of Engineering, Kansai \\ University, Suita, Osaka 564-8680, Japan
}

Title Running Head: ACMSD is a Metalloenzyme

* Corresponding Author: Tel: 601-984-1872, Fax: 601-984-1501, and E-mail: aliu@biochem.umsmed.edu

University of Mississippi Medical Center

${ }^{\S}$ Kansai University

Supporting Information (6 pages) 
Table S1. Input File for the Spectral Simulation of Co-ACMSD at $10 \mathrm{~K}$.

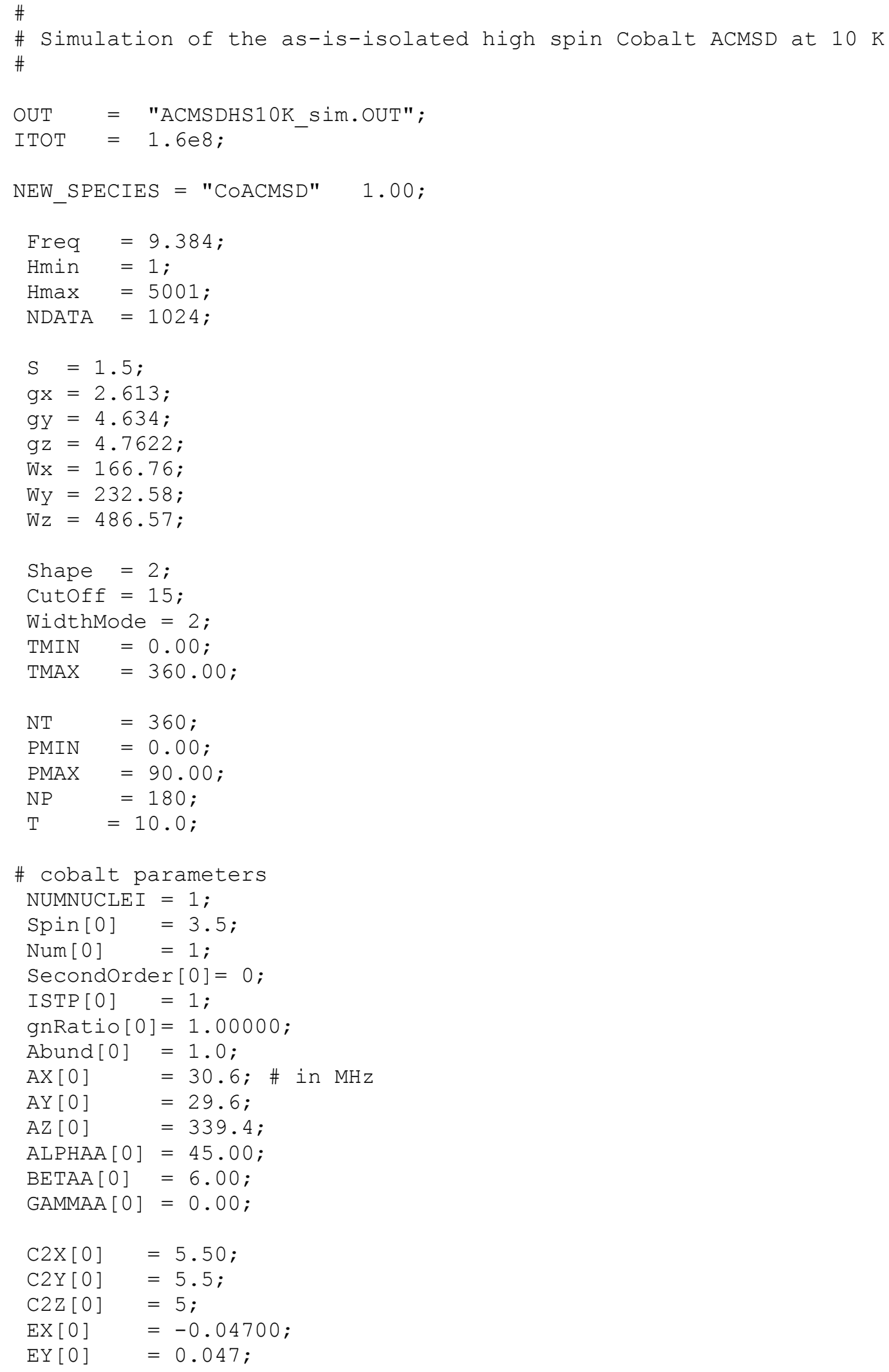




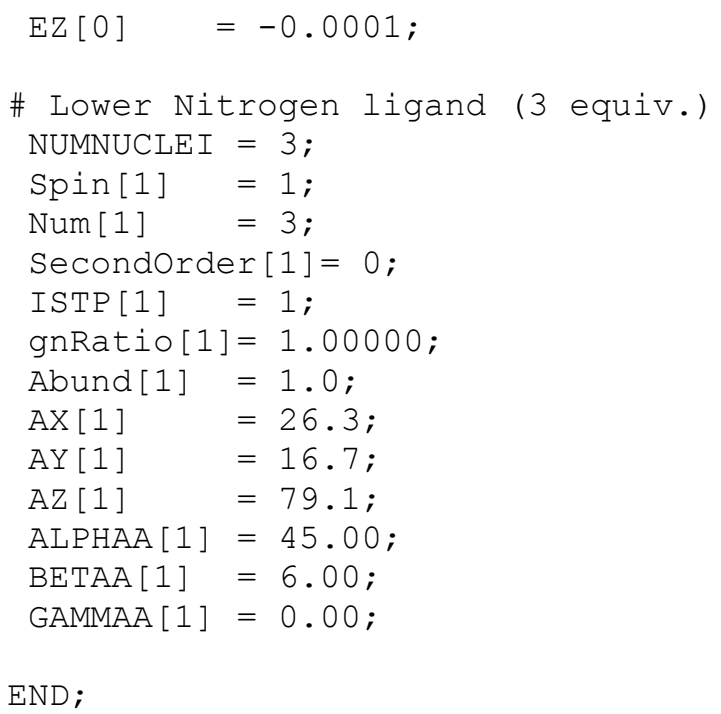

END;

Table S2. Input File For Spectral Simulation of Cu-ACMSD.

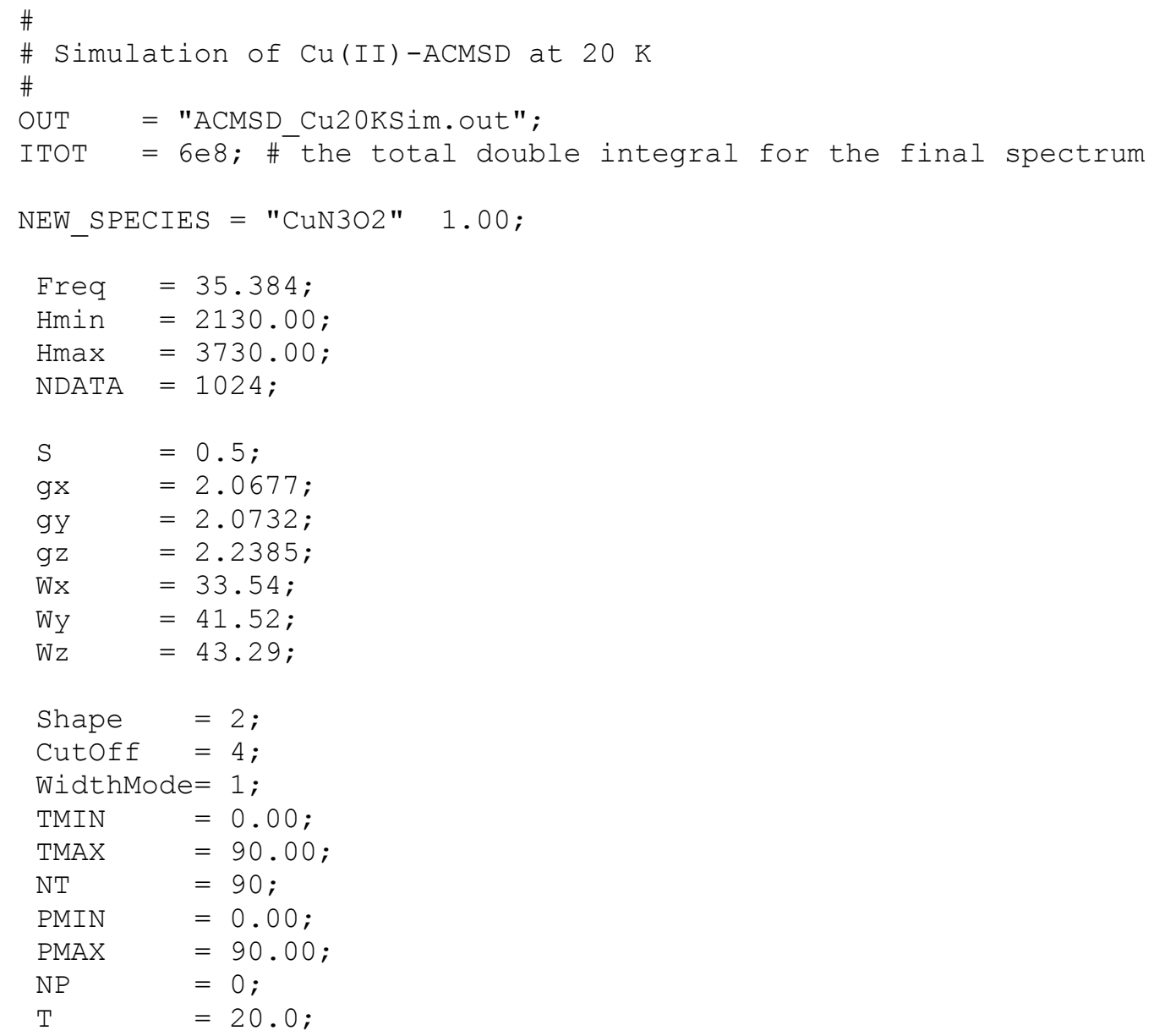




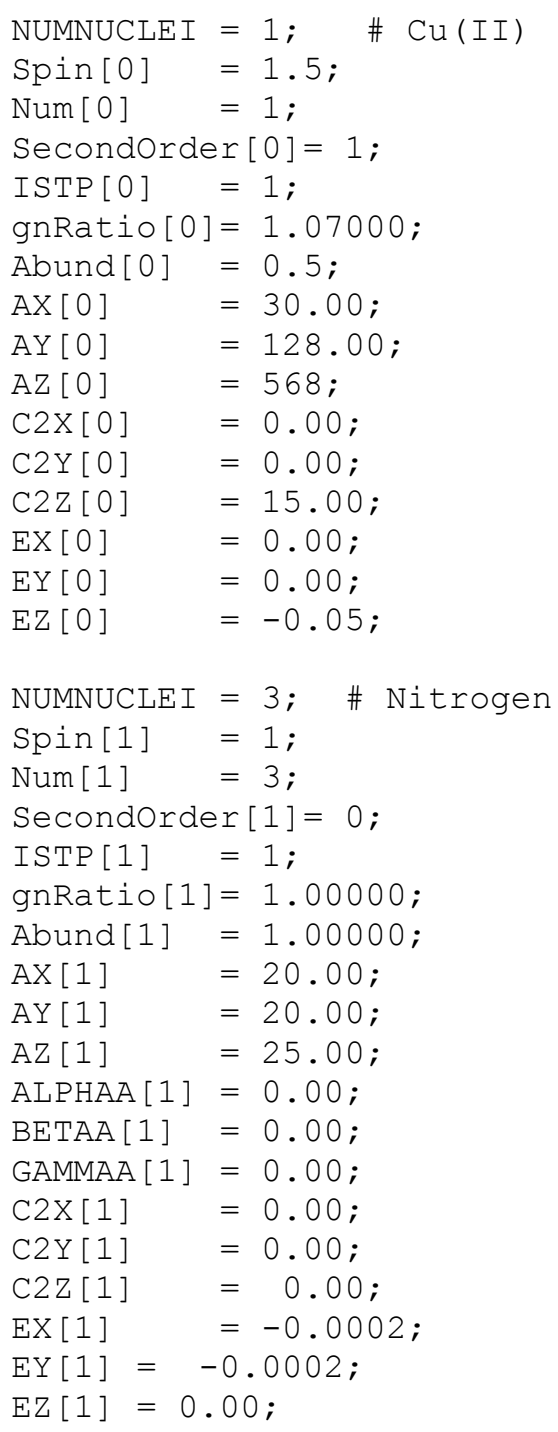

END; 
Figure S1. A Screenshot of the SimFonia Predictions Using the $g$ and $A$ Principal Values from the Spectral Simulation at $10 \mathrm{~K}$ (Table 2).

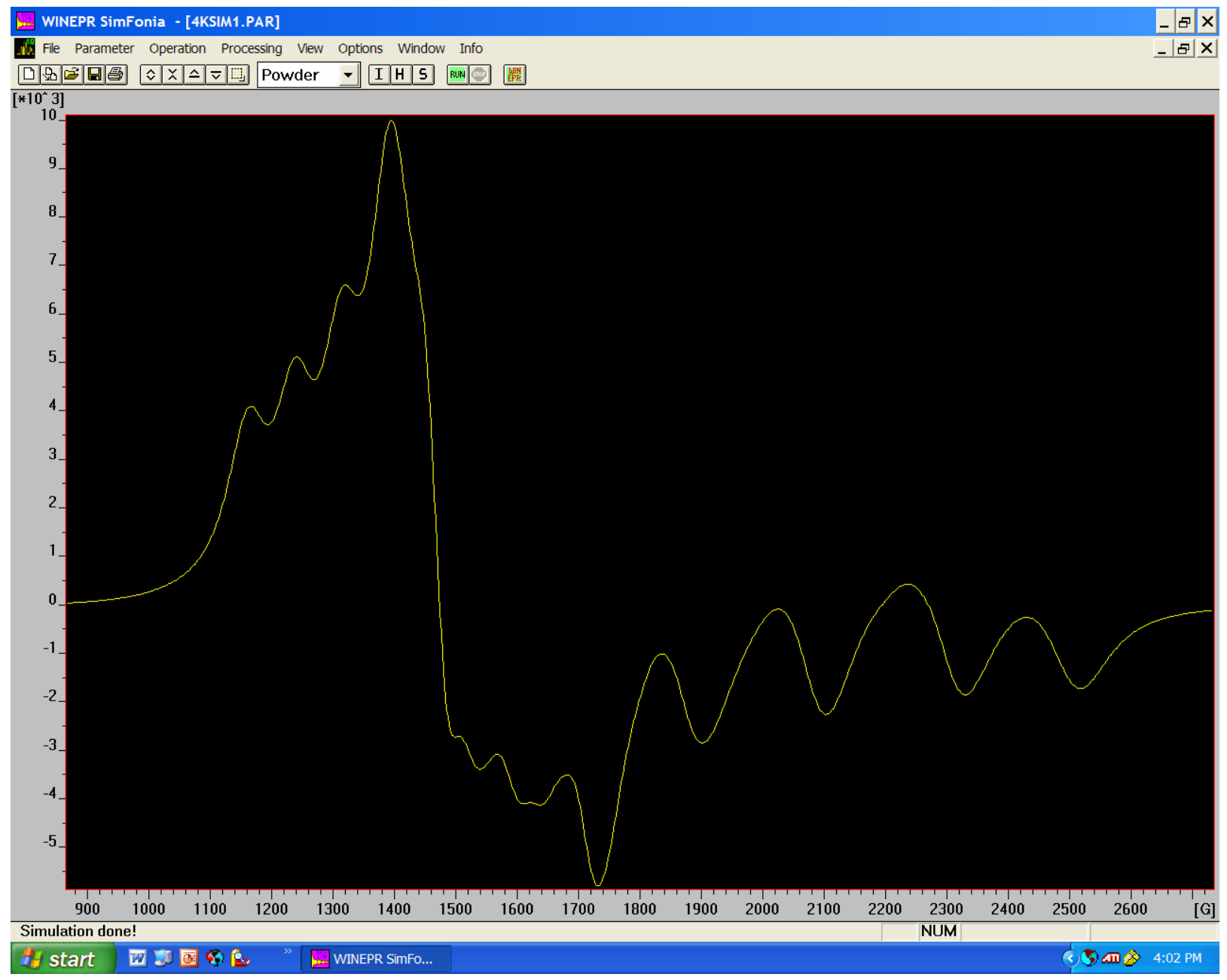


Figure S2. Multiple Sequence Alignment of Representative ACMSD Protein Sequences.

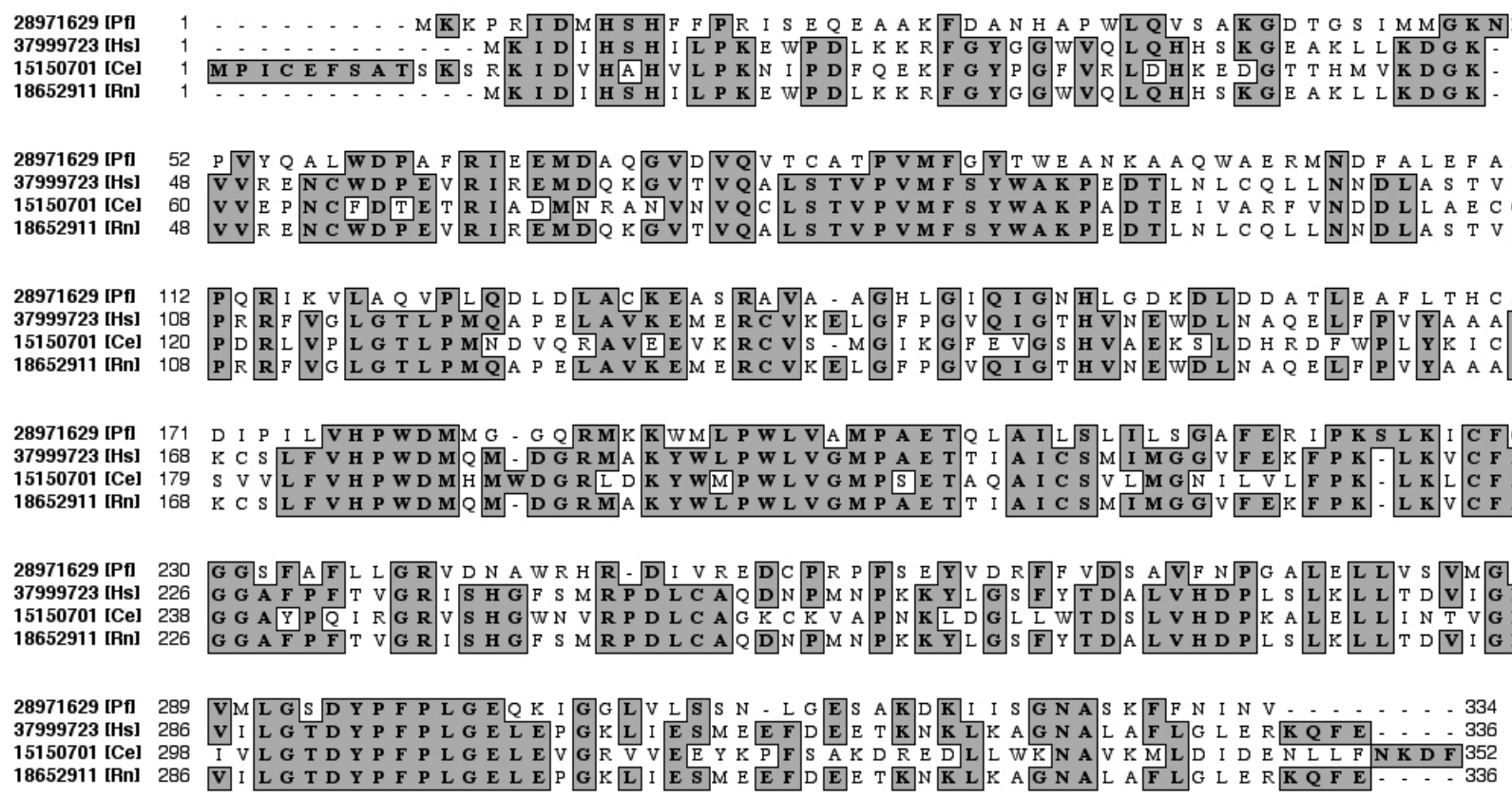

Sequences are labeled according to the NCBI gene identification (gi) number and species name. Abbreviations of species names are: Pf, Pseudomonas fluorescens; Hs, Homo sapiens; Ce, Caenorhabditis elegans; Rn, Rattus norvegicus. 